\title{
Comparison of methods for the diagnosis of typhoid fever
}

\author{
R Duthie, G L French
}

\begin{abstract}
Over five years the Bactec radiometric blood culture method yielded Salmonella typhi in 41 of 45 confirmed cases of typhoid fever, $90 \%$ of which were from the first culture set taken. Blood clot culture was positive in $18(41 \%)$ of 44 confirmed cases and stool culture in 24 $(59 \%)$ of 41 . The yield from 2189 Widal clot cultures was only $0.03 \%$. There were 68 positive results in 2258 unpaired Widal tests: 23 of them were falsely positive and 13 falsely negative, but in 11 out of 68 cases the Widal was the only positive laboratory test. It is concluded that routine clot culture is not cost effective if a sensitive blood culture method is used, and that the Widal test is useful only in selected patients.
\end{abstract}

The incidence of typhoid fever in Hong Kong is about 4.6 per 100000 of the population. ${ }^{1}$ The diagnosis is usually confirmed by culture of blood, blood clot, or stool, together with the results of the Widal agglutination test. The usefulness of the Widal test has been questioned. ${ }^{2-7}$ In most cases only a single titre is obtained. Repeating the test may increase the number of positive results, ${ }^{4}$ but there is often neither an initial increase nor a rise in titres, even in culture positive typhoid fever. Furthermore, the results of the test are invalidated by a previous history of vaccination or typhoid fever. ${ }^{8}$ This study examines the relative contributions of each of these four laboratory investigations to the diagnosis of typhoid fever in Hong Kong over a five year period.

\section{Methods}

Results of Widal agglutination tests and Salmonella typhi cultures performed between April 1984 and December 1989 were obtained by retrospective analysis of laboratory records. There were very few paratyphoid infections, which were excluded from the study. Patients with a single positive Widal test with a previous history of typhoid fever or vaccination were also excluded. True positive, false positive, and false negative Widal results were determined by reviewing patient records, culture results, and notifiable disease returns.

Widal agglutination was performed using Wellcome reagents (Wellcome Diagnostics, Dartford) containing $\mathrm{O}$ and $\mathrm{H}$ antigens of $S$ typhi. A dilution series of 1 in 50 to 1 in $4 \overline{0} 0$ of serum in $0.85 \%$ saline was made, and $0.3 \mathrm{ml}$ of each dilution was added to $0.3 \mathrm{ml}$ of antigen suspension. Positive and negative serum controls were included. The tubes were incubated in a $56^{\circ} \mathrm{C}$ water bath for 18 hours before reading. A titre of $>1 / 100$ to either antigen in a single serum specimen was taken to be indicative of typhoid fever. ${ }^{9}$ The laboratory participates in the external quality control programme of the Royal College of Pathologists of Australia and achieves consistently good results for Widal tests.

After removal of serum for the Widal agglutination test the blood clot was placed in $10 \mathrm{ml}$ of $0.5 \%$ bile salt broth (Oxoid, Basingstoke) for culture. After two days of incubation at $37^{\circ} \mathrm{C}$ the broth was subcultured to DCA and MacConkey agar plates (Oxoid). Negative cultures were terminally subcultured on day 6.

Blood cultures were made with the Bactec 460 radiometric system (Johnson Laboratories, Towson, Maryland), using the $6 \mathrm{~B}$ aerobic and $7 \mathrm{D}$ anaerobic broth media. The blood:broth ratio was about $1: 6$. The cultures were examined daily for six days before being discarded.

Stool specimens were plated directly on DCA and MacConkey agar (Oxoid) and inoculated into Selenite F broth (Oxoid) for enrichment culture.

Isolates were confirmed to be $S$ typhi by their API20E profile (Anylab Products, Plainview, California) and by agglutination with salmonella agglutinating sera (Wellcome).

\section{Results}

There were 63 confirmed cases of typoid fever during the study. In 54 the diagnosis was confirmed by culture: 45 of these were blood positive, 18 clot positive, and 24 stool positive (table 1). In those patients in whom blood culture was performed, 45 of $49(92 \%)$ yielded $S$ typhi. The yield for blood clot culture was 18 of $44(41 \%)$ and for stool culture 24 of $41(59 \%)$. Of the 45 blood culture positive cases, $41(90 \%)$ were diagnosed on the first culture performed. The modal time for the blood cultures to become positive was two days.

Over the same period 2258 assessable single Widal agglutination tests were performed. Sixty eight were positive $(0.03 \%)$, of which 23 were false positive. There were 13 culture positive cases of typhoid fever in whom the Widal test was falsely negative. Eleven cases 
Table 1 Results of blood, stool, and clot culture and Widal agglutination in patients with bacteriologically confirmed typhoid fever

\begin{tabular}{|c|c|c|c|c|c|c|c|c|c|c|}
\hline \multirow{4}{*}{$\begin{array}{l}\text { Blood } \\
\text { culture }\end{array}$} & \multirow{4}{*}{$\begin{array}{l}\text { Clot } \\
\text { culture }\end{array}$} & \multicolumn{9}{|c|}{ Widal test } \\
\hline & & \multicolumn{3}{|c|}{ Positive } & \multicolumn{3}{|c|}{ Negative } & \multicolumn{3}{|c|}{ Not done } \\
\hline & & \multicolumn{9}{|c|}{ Stool culture } \\
\hline & & + & - & Not done & + & - & Not done & + & - & Not done \\
\hline+ & - & 6 & 2 & 1 & 2 & 1 & 1 & 1 & & \\
\hline+ & - & 6 & 9 & 4 & 2 & & 2 & & 1 & \\
\hline+ & ND & & 1 & 2 & 1 & & & 1 & 1 & 1 \\
\hline- & + & & 1 & 1 & & 1 & & & & \\
\hline- & - & & & & 1 & & & & & \\
\hline ND & + & & & 1 & & & & & & \\
\hline ND & - & & & & 1 & & & & & \\
\hline ND & ND & & & & 1 & & & 2 & & \\
\hline
\end{tabular}

$\mathrm{ND}=$ Not done routine method.

In our study clot culture had a yield of only $41 \%$. In one out of 65 laboratory confirmed cases, the clot culture was the only test which gave a positive result. Some workers have found that the addition of streptokinase increases the yield of clot cultures, but others have failed to confirm this. ${ }^{16}$ We did not use streptokinase, but many of our clots were already autolysed before inoculation into bile salt broth. In our laboratory the yield for routine clot culture is low $(0.82 \%)$ and the cost is US $\$ 0.32$ per test. In view of the limited cost effectiveness of this test we do not believe that the routine clot culture of specimens sent for Widal agglutination is justified except when good blood culture facilities are unavailable.

The low yield for stool culture in the initial week of typhoid fever is well known. In this study, however, $6 \%$ of cases were diagnosed by stool culture alone, and this test still has a role.

Only $3 \%$ of more than 2000 Widal tests gave a positive result, and only $2 \%$ were true positive. False negative results occurred in $0 \cdot 6^{\circ}$ of tests. Laboratory confirmation of typhoid fever, however, would not have been made in 11 of $65(17 \%)$ cases had the test not been performed.

Quality control of Widal tests is important: a laboratory which consistently produces poor results in an external quality control programme should discontinue the test until technical problems are solved. ${ }^{17}$ False positive results may be due to faulty technique or to poor quality of the antigen suspension. There is conflicting evidence as to the relative importance of somatic and flagellar agglutinin titres for the diagnosis of typhoid fever, ${ }^{34}$ but in our study both agglutinins gave similar results.

The Widal test should be interpreted in the light of baseline titres in a healthy local population. This is especially important when there is a high local prevalence of non-typhoid salmonellosis. ${ }^{4}$ The Widal test may be falsely positive in patients who have had previous vaccination or infection with $S$ typhi. ${ }^{7}$ Raised Widal titres have also been reported in association with the dysgammaglobulinaemia of chronic active hepatitis and other autoimmune diseases. ${ }^{641819}$ False negative results may be associated with early treatment, with "hidden organisms" in bone and joints, and with relapses of typhoid fever. Occasionally the infecting strains are poorly immunogenic. ${ }^{4}$

Our results suggest that modern blood culture techniques permit the bacteriological confirmation of typhoid fever in a high proportion of cases. Routine clot culture of specimens sent for the Widal test is not cost effective and the Widal test itself should be used more selectively. A single Widal test is not reliable for the diagnosis of typhoid fever because false positive and false negative results are common. In a patient strongly suspected to have typhoid fever it may be useful to perform the Widal test only if two blood cultures are negative.
Discussion
In this study we obtained an isolation rate of
$92 \%$ for blood culture with the Bactec 460
system using a blood:broth ratio of $1: 6$. This
yield is comparable with those reported by
other workers using $10 \%$ Oxgall. ${ }^{10}$ The Bactec
460 media contain liquoid which probably
contributed to the good recovery rates. ${ }^{11} 12$
Some workers claim that bone marrow culture
provides the highest yield of $S$ typhi in the
diagnosis of typhoid fever, ${ }^{13-15}$ but the detec-
tion rate of $84-92 \%$ is no better than our
result for blood culture. The invasive nature
of bone marrow culture precludes its use as a

Discussion
In this study we obtained an isolation rate of
$92 \%$ for blood culture with the Bactec 460
system using a blood:broth ratio of $1: 6$. This
yield is comparable with those reported by
other workers using $10 \%$ Oxgall. ${ }^{10}$ The Bactec
460 media contain liquoid which probably
contributed to the good recovery rates. ${ }^{11} 12$
Some workers claim that bone marrow culture
provides the highest yield of $S$ typhi in the
diagnosis of typhoid fever, ${ }^{13-15}$ but the detec-
tion rate of $84-92 \%$ is no better than our
result for blood culture. The invasive nature
of bone marrow culture precludes its use as a

Discussion
In this study we obtained an isolation rate of
$92 \%$ for blood culture with the Bactec 460
system using a blood:broth ratio of $1: 6$. This
yield is comparable with those reported by
other workers using $10 \%$ Oxgall. ${ }^{10}$ The Bactec
460 media contain liquoid which probably
contributed to the good recovery rates. ${ }^{11} 12$
Some workers claim that bone marrow culture
provides the highest yield of $S$ typhi in the
diagnosis of typhoid fever, ${ }^{13-15}$ but the detec-
tion rate of $84-92 \%$ is no better than our
result for blood culture. The invasive nature
of bone marrow culture precludes its use as a

Discussion
In this study we obtained an isolation rate of
$92 \%$ for blood culture with the Bactec 460
system using a blood:broth ratio of $1: 6$. This
yield is comparable with those reported by
other workers using $10 \%$ Oxgall. ${ }^{10}$ The Bactec
460 media contain liquoid which probably
contributed to the good recovery rates. ${ }^{11} 12$
Some workers claim that bone marrow culture
provides the highest yield of $S$ typhi in the
diagnosis of typhoid fever, ${ }^{13-15}$ but the detec-
tion rate of $84-92 \%$ is no better than our
result for blood culture. The invasive nature
of bone marrow culture precludes its use as a

Discussion
In this study we obtained an isolation rate of
$92 \%$ for blood culture with the Bactec 460
system using a blood:broth ratio of $1: 6$. This
yield is comparable with those reported by
other workers using $10 \%$ Oxgall. ${ }^{10}$ The Bactec
460 media contain liquoid which probably
contributed to the good recovery rates. ${ }^{11} 12$
Some workers claim that bone marrow culture
provides the highest yield of $S$ typhi in the
diagnosis of typhoid fever, ${ }^{13-15}$ but the detec-
tion rate of $84-92 \%$ is no better than our
result for blood culture. The invasive nature
of bone marrow culture precludes its use as a 
1 Director of Medical and Health Services. 1988-1989 Departmental Report. Hong Kong: Government Printer, 1989.

2 Sen R, Saxena SN. Critical assessment of conventiona Widal test in the diagnosis of typhoid and paratyphoid fever. Ind J Med Res 1969;57:1-7.

3 Brodie J. Antibodies and the Aberdeen typhoid outbreak of 1964. I The Widal reaction. J Hyg (Camb) $1977 ; 79$. 161-81.

4 Senewiratne B, Senewiratne K. Reassessment of the Widal test in the diagnosis of typhoid fever. Gastroenterol test in the diagn
$1977 ; 73: 233-6$.

5 Shehabi AA. The value of a single Widal test in the diagnosis of acute typhoid fever. Trop Geogr Med 1981;33:113-6.

$6 \mathrm{Pu}$ SJ, Huang HS. Diagnostic value of a single Widal test. Chin J Microbiol Immunol 1985;18:256-63.

7 Pang T, Puthucheary SD. Significance and value of Widal test in diagnosis of typhoid fever in an endemic area. $\mathrm{JClin}$ Pathol 1983;36:471-5.

8 Felix A. The qualitative receptor analysis in its application to typhoid fever. J Immunol 1924;9:115-91.

9 Chow CB, Wang PS, Cheung MW, et al. Diagnostic value of the Widal test in childhood typhoid fever. Pediatr Infect Dis $J 1987 ; 81: 374-7$.

10 Simanjuntak CN, Hoffman SL, Darmowigoto R, et al. Streptokinase clot culture compared with whole blood culture for isolation of Salmonella typhi and $S$ paratyphi $A$ culture for isolation of Salmonella typhi and S paratyphi A
from patients with enteric fever. Trans $R$ Soc Trop Med Hyg 1988;82:340-1.

11 Watson KC. Laboratory and clinical investigation of recovery of $\mathrm{S}$ typhi from blood. J Clin Microbiol 1978;7:122-6.

12 Foster WD. Laboratory diagnosis of typhoid fever. Lancet 1975 ;ii:80.

13 Vallenas C, Hernandez H, Kay B, et al. Efficacy of bone marrow blood, stool and duodenal contents culture for bacteriologic confirmation of typhoid fever. Paediatr Infect Dis 1985;4:496-8.

14 Gilman RH, Terminel M, Levine MM, et al. Relative efficacy of blood, urine, rectal swab, bone marrow and rose spot cultures for recovery of Salmonella typhi in typhoid spot cultures for recovery of
fever. Lancet $1981 ; \mathrm{i}: 1211-3$.

15 Hofmann SL, Edman DC, Punjabi NH, et al. Bone marrow aspirate superior to streptokinase clot culture and $8 \mathrm{~m}$ $1: 10$ blood-to-broth culture for the diagnosis of typhoid fever. Am J Trop Med Hyg 1986;35:836-9.

16 Watson KC. Fate of $S$ typhi in blood clot in relation to problems of isolation. J Clin Pathol 1955;8:52-4.

17 RCPA Quality Assurance Programmes PTY LTD. Microbiology survey M4/89: General comments. Item: 89:4:7A,B. RCPAQAP. Sydney: Royal College of Pathologists of Australia.

18 Capron JP, Soloway RD, Martin WJ, et al. False positive Widal test in HBs antigen associated polyarteritis nodosa. Gastroenterol 1978;75:770.

19 Protell RL, Soloway RD, Schoenfield W, et al. Anti-salmonella agglutinins in chronic active liver disease. Lancet 1971;ii:330-2. 